\title{
Risperidone long-acting injection: a review of its long term safety and efficacy
}

\author{
Michael K Rainer \\ Memory-Clinic and Psychiatric \\ Department, Donauspital, Vienna, \\ Austria
}

\begin{abstract}
A long-acting form of the second-generation antipsychotic drug risperidone is now broadly available for the treatment of schizophrenia and closely related psychiatric conditions. It combines the advantage of previously available depot formulations for first-generation drugs with the favorable characteristics of the modern "atypical" antipsychotics, namely higher efficacy in the treatment of the negative symptoms of schizophrenia and reduced motor disturbances. Published clinical studies show an objective clinical efficacy (as per psychiatric symptom scores and relapse data) that exceeds that of oral atypical antipsychotics when patients are switched to the long-acting injectable form, a low incidence of treatment-emergent extrapyramidal side effects, and very good acceptance by patients. Available data for maintenance treatment of bipolar disorder show equivalence with the oral form instead of superiority, but are still limited. As it seems likely that efficacy benefits are mostly due to the fact that the injectable form reduces the demand for patient compliance to one physician visit every 2 weeks instead of self-administration on a daily or twice-daily basis, additional potential could exist in other psychiatric disorders where atypical antipsychotic drugs are of benefit but where patient adherence to treatment schedules is typically low.
\end{abstract}

Keywords: risperidone, schizophrenia, psychotic disorders, patient compliance; delayed-action preparations, injections, intramuscular

\section{Depot antipsychotics: a necessity in a patient population inclined towards non-compliance}

Premature discontinuation of antipsychotic drug therapy is a common phenomenon: in the Clinical Antipsychotic Trials of Intervention Effectiveness (CATIE) study, 74\% of patients discontinued their drug within 18 months due to either poor tolerability or lack of efficacy (Lieberman et al 2005). Even among those who do not explicitly discontinue drug therapy, non-adherence to long-term oral medication regimes is one of the most significant therapeutic issues in the therapy of schizophrenia and related disorders (Kane 2007; Byerly et al 2007). As a result, many of these patients do not experience the full benefit of antipsychotic drug therapy, and suffer frequent relapses or exacerbations which require rehospitalization, often in the context of psychiatric emergency.

The consensus of many estimates in the literature places the fraction of outpatients who are at least to some significant degree non-adherent to their antipsychotic therapy scheme at $40 \%$ or higher. Medication adherence during the early course of schizophrenia is a strong predictor of long-term clinical outcome (Kane 2007; Bachmann et al 2008), but neither the individual patients themselves nor their psychiatrists seem able to reliably identify the degree of compliance with oral antipsychotic drug regimes (Velligan et al 2007). Failure to establish a therapeutic alliance with medical staff during acute hospitalization, lack of insight into the pathological nature of the symptoms of schizophrenia, concomitant substance abuse, and absence of family support are the most 
significant predictors of outpatient non-compliance (Olfson et al 2000). In a retrospective survey (Knapp et al 2004), those patients who self-reported non-adherence (likely only a fraction of those who deny non-adherence or are unaware of it) were much more likely to report use of inpatient services, and their external service cost is several times higher than for patients who state that they are compliant with antipsychotic medication regimes. Correlation analyses of pharmacy refill records and hospitalization statistics confirm this (Gilmer et al 2004).

A steadily growing body of literature addresses this complex behavioral problem, in which factors related to the underlying psychiatric condition and adverse drug side effects are but two elements, with personal beliefs and attitudes, psychosocial environment factors, and availability of healthcare resources also making decisive contributions. A recently published review (Weiden 2007) has stated very succinctly that if an easy answer to the problem of medication non-adherence in schizophrenia existed, it would have already been found.

Even during the early times of antipsychotic drug therapy, developers realized that depot formulations of antipsychotic drugs which can provide therapeutic plasma levels for several weeks after a single intramascular injection could offer a way to partially circumvent the problem of noncompliance in the therapy of schizophrenia. Such formulations of first-generation antipsychotics which employ long-chain alkanoic acid (decanoate and/or enanthate) salts of haloperidol, fluphenazine, perphenazine, flupenthixol, clopenthixol, and zuclopenthixol in plant oils became available from the 1960s onward. The slow-release pharmacokinetics of these long-acting injectable (LAI) drugs (Jann et al 1985) made it possible to discharge stabilized but potentially non-compliant patients who would then have to return only once per month to receive their next depot injection (McEvoy 2006).

Use of classical depot antipsychotics declined in the 1990 s, a development that has been partially attributed to the introduction of the second-generation ("atypical") antipsychotic drugs which exhibit higher efficacy with respect to the treatment of negative symptoms of schizophrenia and reduced liability for motor side effects. However, these newer drugs were initially available as oral formulations only. By the first years of the new millennium, psychiatrists were aware that, although patients treated with second-generation antipsychotics showed moderately better therapy adherence than those treated with older drugs, additional measures were required for those newer drugs as well (Dolder et al 2002), with long-acting formulations being the natural choice.

\section{Formulation and pharmacological characteristics of risperidone long-acting injection}

The LAI formulation of the well-established oral atypical antipsychotic risperidone became available in Europe from August 2002 onward, and was launched in the US in December 2003. It had been developed by the Janssen Research Foundation (Beerse, Belgium; a member of the Johnson and Johnson group of companies) using the Medisorb ${ }^{\text {TM }}$ formulation technology provided by drug delivery specialist Alkermes, Inc. (Cambridge, Mass., USA). Risperidone LAI uses micrometer-sized biodegradable poly(d,l-lactide-coglycolide) microspheres which are loaded with risperidone and suspended in sterile saline. There is no significant drug release immediately after injection; substantial release of risperidone into plasma begins only at 2 to 3 weeks post injection, increases during weeks 3 and 4 , is maintained during weeks 4 through 6 , and declines between weeks 6 and 7 . With repeated injections every 2 weeks, steady-state levels are usually reached by weeks 6 to 8 (Knox and Stimmel 2004). Details on the plasma pharmacokinetic profile (Eerdekens et al 2004; Mannaert et al 2005) and on brain dopamine D2 receptor occupancy (Gefvert et al 2005; Remington et al 2006) have been published, showing bioequivalence between the oral and LAI versions but with reduced peak-trough fluctuations in plasma levels of risperidone and its active metabolite, 9-hydroxyrisperidone (Nesvag et al 2006) which has been developed into a follow-on drug for risperidone (see separate section). Although similar experimental drug delivery systems have been reported for chlorpromazine (Suzuki and Price 1985) and haloperidol (Cheng et al 1998), no such formulation of any classical neuroleptic has ever reached the pharmacy shelves and Risperdal Consta was the first atypical antipsychotic to become available as a LAI version.

\section{Efficacy and safety data}

The first data on clinical efficacy and safety were initially presented in May 2001, and full results were subsequently published. In a 4-arm, 3-month, randomized, double-blind, placebo-controlled study conducted at 41 medical centers in the United States (Kane et al 2003), all $4 \times 100$ patients with schizophrenia were first started on oral risperidone (maximum daily dose, $4 \mathrm{mg}$ ) and continued to receive oral risperidone for a total of 4 weeks. Patients in 3 study arms received 1 of 3 doses of risperidone LAI ( $25 \mathrm{mg}, 50 \mathrm{mg}$, or $75 \mathrm{mg}$ ) every 2 weeks, while the fourth was injected with placebo. Treatment with other antipsychotics was not permitted. 
Patients who showed signs of relapse were removed from the study. All risperidone LAI treatment groups experienced significantly greater improvements in their total Positive and Negative Symptom Scale (PANSS; the primary efficacy outcome measure) scores than those who received placebo (mean changes, $-6.2,-8.5$, and -7.4 for the three doses; $p=0.002$ for all doses). There were also more positive responses for risperidone LAI versus placebo for all of the secondary measures used in the study, including the PANSS subscales for positive and negative symptoms, the percentage of patients who experienced symptom improvement of at least $20 \%$, and time to dropout due to lack of efficacy. Thirty percent more patients on placebo, as opposed to $22 \%, 16 \%$, and $12 \%$ for $25 \mathrm{mg}, 50 \mathrm{mg}$, and $75 \mathrm{mg}$, withdrew from the study due to insufficient treatment response.

All doses were generally well tolerated. The percentage of patients who dropped out of the study due to side effects after receiving risperidone LAI in addition to the oral drug was $11 \%$ for $25 \mathrm{mg}$ of risperidone LAI, $12 \%$ for $50 \mathrm{mg}$ and $14 \%$ for $75 \mathrm{mg}$, comparable to the discontinuation rate for additional placebo (12\%). At the highest dose of risperidone LAI (without oral supplementation), the most common side effects that were reported with significantly higher freqency by patients on risperidone LAI were headache ( $18 \%$ for risperidone patients vs $13 \%$ for those receiving placebo), sleepiness ( $11 \%$ vs $2 \%)$, and anxiety (11\% vs $7 \%)$. Remarkably with respect to cardiac safety, there were fewer cases of QTc prolongation among patients taking all doses of risperidone LAI than among those taking placebo.

A subanalysis of 214 patients who were inpatients at study initiation (Lauriello et al 2005) showed risperidone LAI to be associated with a significant reduction in total PANSS score (mean change \pm standard error at endpoint: risperidone LAI, $-9.27 \pm 1.44, \mathrm{n}=133$; placebo, $0.72 \pm 2.59$, $\mathrm{n}=41 ; \mathrm{p}<0.001$ ), and a significantly higher rate of treatment response, defined as $\geq 20 \%$ reduction in total PANSS score $(50 \%$ vs $27 \%, \mathrm{p}<0.05)$.

Results from a larger (116 centers in 16 countries) study of much longer treatment duration (50 weeks), which, however, used an open label design, were first reported in December 2001, and were later published in a long series of peer-reviewed papers (Fleischhacker et al 2003, 2005; Lasser et al 2004a, b, 2005; Leal et al 2004; Gharabawi et al 2005). The study was conducted from March 1999 to July 2000, and apart from not being blinded its design was similar to the study described previously. During a 2-week run-in period, patients were withdrawn from their prescribed antipsychotic (if different from risperidone) and received oral risperidone at $1-6 \mathrm{mg} / \mathrm{day}$. Patients continued to take oral risperidone for another 2-4 weeks after injections of risperidone LAI (25, 50, or $75 \mathrm{mg}$ every 2 weeks) began to assure that therapeutic blood levels of the drug were achieved prior to the halt in oral treatment. A total of 725 symptomatically stable patients with schizophrenia $(n=615)$ or schizoaffective disorder $(n=110)$ received at least 1 injection. Sixty-five percent $(n=474)$ completed the study, receiving injections for a full 50 weeks. The primary measure of efficacy was the PANSS. Global illness severity and patient-rated health status were measured using the Clinical Global Impressions (CGI) scale and the 36-Item Short-form (SF-36) Health Survey, respectively. Dyskinesia and other movement disorders, as rated by the Extrapyramidal Symptom Rating Scale (ESRS), were minimal: Five of 530 subjects without dyskinesia at baseline $(0.94 \%)$ met the predefined criteria for emergent persistent tardive dyskinesia during therapy. Based on either exposure to study medication or Kaplan-Meier analysis, the 1 -year rate was $1.19 \%$. Among the 132 subjects with dyskinesia at baseline, the mean score on the ESRS physician's exam for dyskinesia improved significantly at endpoint $(-2.77 ; \mathrm{p}<0.0001)$, regardless of anticholinergic drug use (Gharabawi et al 2005).

Remission (as defined by mild or better multiple coresymptom ratings for at least 6 months) was achieved in $20.8 \%$ of those patients who did not meet the symptom-severity component of remission criteria at baseline, with significant decreases in mean PANSS total and cluster scores. In these patients, endpoint changes from baseline were $-4.8 \pm 0.6$ for positive symptoms; $-5.9 \pm 0.5$ for negative symptoms; $-3.7 \pm 0.4$ for disorganized thoughts; $-2.5 \pm 0.4$ for anxiety and depression, and $-1.4 \pm 0.3$ for excitement and hostility (mean \pm standard error; $\mathrm{p}<0.0001$ for all scores). Patientrated health status was also significantly improved. Percentages rated as not ill, very mildly, or mildly symptomatic increased from 39\% to $88 \%$. Among 31.8\% (184/578) of patients meeting the symptom-severity component of remission criteria at baseline, $84.8 \%$ (156) maintained these criteria at endpoint (Lasser et al 2005).

Only 5\% of patients with schizophrenia dropped out of the study due to side effects, and although extrapyramidal symptoms were reported by $25 \%$ of the patients spontaneously reported tardive dyskinesia occurred in fewer than $1 \%$ of patients overall, and severity scores decreased in each of the groups during the 12 months of treatment. The other most common adverse events were anxiety in $24 \%$, insomnia in $21 \%$, psychosis in $17 \%$, and depression in $14 \%$ of the patients. No medically relevant cases of QTc prolongation 
were observed. Injection site pain (a typical complaint with the oil-based depot formulations of first-generation antipsychotics) was reported by just two percent of patients who received risperidone LAI, consistent with the 12-week study. There was a modest increase of body weight (average for all doses of risperidone LAI, $2.5 \mathrm{~kg}$ ) at the end of the treatment year. Healthcare resource utilization declined significantly during this study. The number of patients needing any type of hospitalization decreased exponentially from $38 \%$ during the 12 weeks before study entry to $12 \%$ during the last 12 weeks. Outpatient consultations also decreased significantly from $70 \%$ of patients to $30 \%$ in the first 12 weeks of treatment and remained stable thereafter (Leal et al 2004).

Data were collected for a prospective, double-blind, randomized 1-year study (Simpson et al 2006) using the two approved doses of risperidone LAI from December 2002 to September 2004. Time to relapse, defined as either re-hospitalization or other exacerbation criteria, was the primary outcome. Other assessments included the PANSS, CGI-Severity of Illness scale, and functional and quality-of-life measures. Safety was assessed via treatment-emergent adverse events, laboratory tests, and movement disorder rating scales. A total of 324 patients were randomized to $25 \mathrm{mg}(\mathrm{N}=163)$ or $50 \mathrm{mg}(\mathrm{N}=161)$ of long-acting risperidone. Time to relapse was comparable $(p=0.131)$ for both groups. Projected median time to relapse was 161.8 weeks $(95 \% \mathrm{CI}=103.0-254.2)$ with $25 \mathrm{mg}$ and 259.0 weeks $(95 \% \mathrm{CI}=153.6-436.8)$ with $50 \mathrm{mg}$. One-year incidences of relapse were $21.6 \%(\mathrm{~N}=35)$ and $14.9 \%(\mathrm{~N}=24)$, respectively $(\mathrm{p}=0.059)$. Psychiatric hospitalization was the reason for relapse for $16(10 \%)$ in the $25-\mathrm{mg}$ group and $10(6 \%)$ in the 50-mg group. Patients experienced statistically significant but modest improvements at endpoint in most measures (ie, psychotic symptoms, functioning, movement disorder severity) with both doses, with no significant between-group differences.

\section{Direct transition from oral antipsychotics to risperidone LAI: the StoRMi trial}

An important issue for the acceptance of a new therapeutic option in clinical practice is how smoothly the transition from existing medications to the new one can be performed, and whether there are efficacy or safety problems to be expected during the switching process or during the subsequent maintenance treatment. Initial promising information on this potential issue with risperidone LAI had already been provided by a 12 -week multicentric open-label study
(Lindenmayer et al 2004). Full-scale evaluation was the objective of the open-label, single-arm Switch To Risperidone Microspheres (StoRMi) trial which was performed at 324 centers in 22 European countries between December 2001 and March 2004 (Moller et al 2005). Patients with schizophrenia or other psychotic disorders received gluteal injections of risperidone LAI $25 \mathrm{mg}$ every 2 weeks for 6 months, without a run-in period with oral risperidone. Any stable oral antipsychotic therapy was allowed at enrollment; only patients who had been treated with clozapine during the previous 3 months, or who had known intolerance for risperidone, were excluded. After 24 weeks the dose could be increased to $37.5 \mathrm{mg}$ or $50 \mathrm{mg}$ in biweekly intervals. All patients continued on their previous antipsychotic regimen for the first 3 weeks of risperidone LAI treatment. Of 1876 patients enrolled, $74 \%$ completed the 6-month study and $22 \%$ received oral risperidone supplementation (mean modal dose, $3.2 \pm 2.4 \mathrm{mg}$ /day for a mean duration of $43.0 \pm 42.0$ days. There was a significant reduction from baseline to endpoint in mean total PANSS score (from $73.4 \pm 22.3$ at baseline to $63.1 \pm 22.8$ at endpont; $\mathrm{p}<0.001$ ), with $38 \%$ of patients having a $20 \%$ or higher improvement. The scores on all PANSS subscales and symptom factors also improved significantly $(p<0.001)$. These benefits were achieved regardless of symptom severity at baseline. The CGI severity score also improved significantly $(3.9 \pm 1.1$ vs $3.3 \pm 1.3 ; \mathrm{p}<0.001)$, as did the mean Global Assessment of Function score. It is important to note in this context that one third of all patients had been changed to risperidone LAI from their original oral treatment because of insufficient efficacy.

Transition to risperidone LAI and continued treatment was tolerated very well, both objectively and in the patient's own impression. The proportion of patients who rated their satisfaction with treatment as "very good" increased from $6 \%$ to $31 \%$. All factors on the SF-36 questionnaire improved; at endpoint, the scores at endpoint for Bodily Pain, Vitality, and the Physical Component Summary approached the normative values for the US population. Movement disorders were reported as treatment-emergent events by $12 \%$ of patients. However, the proportion of patients reporting onset of a movement disorder decreased from $4 \%$ during the first month of treatment to $1 \%$ during months 4-6. ESRS scores showed continuous improvements throughout the study period, from 6.0 points at baseline to 2.8 points at month 6 . The Parkinsonism subscore of the ESRS paralleled this development. Of the 15 deaths that occurred during the study, 5 were attributable to cardiac arrest or other cardiovascular causes, which is consistent 
with myocardial mortality rates typically observed in schizophrenia studies.

Apart from this comprehensive report by Moller et al (2005), various subgroup analyses have been published which grant valuable insights into the action spectrum of risperidone LAI.

The most significant conclusion to be drawn from the synopsis of the results summarized in Table 1 is that objective treatment benefit, safety, and patient satisfaction were very evenly distributed across the StoRMi population. The schizoaffective disorder subgroup reported by Mohl et al (2004) seems to be the only patient group showing less pronounced response on the PANSS score. However, significant improvements from baseline to endpoint were seen in the mood symptom domains of anxiety/depression (10.4 \pm 4.1 vs $8.7 \pm 3.9)$ and uncontrolled hostility/excitement (7.6 \pm 3.6 vs $6.9 \pm 3.8$ ). The uncertainty concerning the diagnostic reliability for this heterogeneous clinical condition, which many pychiatrists see in a continuum with bipolar disorder, is a factor that must be considered in interpreting these results. Here, too, total ESRS movement disorder scores fell progressively throughout the study, and the reduction was already statistically significant $(\mathrm{p}<0.001)$ at 4 weeks.

Eighteen-month follow-up data on (initially) 529 participants from the StoRMI trial have been published (Llorca et al 2008). The discontinuation rate (as per Kaplan-Meier statistics) was $55.7 \%$, which was to a large part due to the fact that risperidone LAI had meanwhile become commercially available. (As per the study protocol, this terminated followup.) Median time to discontinuation was 15.7 months $(95 \%$ CI, 14.0-17.5). The treatment-emergent adverse event rate was $69 \%$ (comparable to what was seen in the formal part of StoRMI) and only 46 patients $(8.7 \%)$ discontinued treatment due to adverse events. Mean weight gain was minimal $(1.0 \mathrm{~kg})$, and not statistically significant in patients who had a body mass index $>25 \mathrm{~kg} / \mathrm{m}^{2}$ at baseline. Of the patients who had achieved or maintained clinical remission during the first 6 months of risperidone LAI treatment during StoRMI, 94\%

Table I Major published subgroup analyses of the StoRMI trial

\begin{tabular}{|c|c|c|c|c|c|}
\hline Subgroup & $\begin{array}{l}\text { Patient } \\
\text { characteristics }\end{array}$ & $\begin{array}{l}\text { PANSS score mean } \\
\text { changes }\end{array}$ & SF-36 changes etc & $\begin{array}{l}\text { Treatment-emergent } \\
\text { adverse events }\end{array}$ & Reference \\
\hline $\begin{array}{l}\text { Switch from } \\
\text { first-generation } \\
\text { antipsychotic }\end{array}$ & $\begin{array}{l}100 \text { patients } \\
\text { switched from oral } \\
\text { drug, } 565 \text { from } \\
\text { depot medication }\end{array}$ & $\begin{array}{l}-15.3 \pm 17.5 \text { for switch } \\
\text { from oral drug; }-9.1 \pm \\
19.5 \text { for switch from } \\
\text { depot drug }\end{array}$ & $\begin{array}{l}\text { CGI-S, GAF, SF- } 36 \\
\text { improved on all meaures }\end{array}$ & $\begin{array}{l}58.0 \% \text { for switch from } \\
\text { oral drug; } 60.4 \% \text { for } \\
\text { switch from depot drug }\end{array}$ & $\begin{array}{l}\text { Marinis et al } \\
2007\end{array}$ \\
\hline $\begin{array}{l}\text { Switch from } \\
\text { monotherapy with } \\
\text { Risperdal oral }\end{array}$ & $\begin{array}{l}568 \text { patients }(60 \% \\
\text { men, age } 36-40 \\
\text { yr }) ; 429(75 \%) \\
\text { completed } 6 \text { mo }\end{array}$ & $\begin{array}{l}-11.9 \pm 17.3,-7.7 \pm \\
19.4), \text { and }-8.7 \pm 20.8 \\
\text { for the patients pre- } \\
\text { treated with } 4 \mathrm{mg} \text { or } \\
\text { less, } 4-6 \mathrm{mg} \text {, and }>6 \\
\text { mg oral risperidone }\end{array}$ & $\begin{array}{l}\text { Improvements were } \\
\text { reported in all domains } \\
\text { for the }>6 \mathrm{mg} \text { pre-trial } \\
\text { dosage group, significant } \\
\text { in Role Physical and Role } \\
\text { Emotional }\end{array}$ & $\begin{array}{l}53 \% \text { in the } \leq 4 \mathrm{mg}, 56 \% \\
\text { in the } 4-6 \mathrm{mg} \text {, and } 62 \% \\
\text { in the }>6 \mathrm{mg} \text { pre-trial } \\
\text { oral risperidone dosage } \\
\text { group, resp; } 55 \% \text { overall }\end{array}$ & $\begin{array}{l}\text { Schmauss } \\
\text { et al } 2007\end{array}$ \\
\hline Young adults & $\begin{array}{l}\text { II9 patients (age } \\
18-30 \mathrm{yr})\end{array}$ & Consistently improved & $\begin{array}{l}\text { One third of the patients } \\
\text { considered themselves } \\
\text { to be either 'not ill' } \\
\text { or 'borderline ill' at } \\
\text { endpoint compared with } \\
6 \text { per cent at baseline }\end{array}$ & Not reported & $\begin{array}{l}\text { Saleem et al } \\
2004\end{array}$ \\
\hline Elderly persons & $\begin{array}{l}52 \text { patients (age } \\
65+\mathrm{yr})\end{array}$ & $-15.8 \pm 19.9$ & $\begin{array}{l}\text { Improvements reported } \\
\text { in all domains }\end{array}$ & $69 \%$ & $\begin{array}{l}\text { Kissling et al } \\
2007\end{array}$ \\
\hline $\begin{array}{l}\text { Negative symp- } \\
\text { toms }\end{array}$ & $\begin{array}{l}842 \text { patients with } \\
\text { a PANSS negative } \\
\text { subscale score } \\
\text { of } 2 \text { I or higher, } \\
\text { which was higher } \\
\text { than their positive } \\
\text { subscale score }\end{array}$ & $\begin{array}{l}-15.4 \pm 20.4 \text { for total } \\
\text { PANSS, }-2.2 \pm 5.9 \text { for } \\
\text { pos. subscale, }-6.1 \pm \\
6.3 \text { for neg. subscale }\end{array}$ & $\begin{array}{l}\text { Improvements reported } \\
\text { in all domains }\end{array}$ & $58 \%$ & $\begin{array}{l}\text { Curtis et al } \\
2008\end{array}$ \\
\hline $\begin{array}{l}\text { Schizoaffective } \\
\text { disorder }\end{array}$ & $\begin{array}{l}\text { I } 19 \text { patients } \\
\text { (52\% male, age } \\
22-74 \text { yr) }\end{array}$ & -8.5 & $\begin{array}{l}70 \% \text { reported "good" or } \\
\text { "very good" satisfaction }\end{array}$ & Not reported & $\begin{array}{l}\text { Mohl et al } \\
2004\end{array}$ \\
\hline
\end{tabular}


experienced sustained remission during follow-up. Change in PANSS total score was $-14.7 \pm 23.0$ points $(-3.6 \pm 7.4$ on the positive and $-5.1 \pm 6.8$ on the negative subscale); again, change from baseline to endpoint was highly significant $(p<0.001)$ for each score.

\section{Early-stage schizophrenia}

Patients who experience their first episode of schizophrenia deserve particular attention for several reasons. Their initial treatment represents a key intervention point that might determine the further course of their disease, and they might be more sensitive to side effects from antipsychotic drugs (Weiden et al 2007). From the scientific perspective, these populations offer the valuable opportunity to study the effectiveness and side effects of particular antipsychotic medications unconfounded by prior medication. It has been shown earlier that time to relapse in such patients is significantly longer (466 vs 205 days) if their first treatment is with oral risperidone rather than with haloperidol, and the overall incidence of relapse during the 206-day median treatment period was also significantly lower, $42 \%$ as opposed to $55 \%$ (Schooler et al 2005).

So far only 1 preliminary study has been published (Emsley et al 2008) that examined the efficacy and safety of directly initiated risperidone LAI in 50 previously untreated patients with first-episode psychosis. Almost two thirds of the patients achieved remission, and of the 39 (78\%) who showed a clinical response of $50 \%$, only 4 relapsed. Mean maximum increase in ESRS total score was minimal, at 1.4 points $(95 \%$ CI, 0.61-2.10) There was a unusually marked increase in body mass index $\left(4.8 \pm 3.8 \mathrm{~kg} / \mathrm{m}^{2}\right)$, although more than half of the patients had remained on the lowest recommended dose (25 mg every 2 weeks), but overall treatment was well tolerated. Two other open-label studies investigated patients who were in the early stages of schizophreniform disorders but not necessarily treatment-naive: a subgroup analysis of 66 young adults (Lasser et al 2007) from the much larger 12-month trial (see the section of earlier efficacy and safety data, above), and a 6-month trial in 382 patients at the University of Barcelona who typically had schizophrenia with a median duration of 1 year since diagnosis and required a change from their previous medication, mainly because of non-compliance (42\%) and insufficient efficacy (31\%) (Parellada et al 2005). The subgroup analysis of young patients from the StoRMI trial (Saleem et al 2004) should also be considered in this context.

In the subgroup analysis by Lasser et al (2007), improvement of the PANSS score over time in the young adults (men aged 18-25, women 18-30) was identical to what was seen in older adults. Mean scores on the patients' subjective ESRS severity ratings for movement disorders and the physicians' ratings of parkinsonism were significantly improved, from $3.1 \pm 3.2$ at baseline to $1.6 \pm 2.4$ at endpoint $(\mathrm{p}<0.0001)$ and from $2.2 \pm 2.4$ to $1.1 \pm 1.8(\mathrm{p}<0.0001)$, respectively. Physician ratings of dyskinesia, akathisia, and dystonia were low throughout the study (mean score $<1$ for each). In the Spanish study the total PANSS and all its subscale scores also improved significantly, with $40 \%$ of patients showing a $20 \%$ improvement, and good tolerability of risperidone LAI with no unexpected adverse events.

\section{Clinical trials in non- schizophreniform disorders}

Oral risperidone carries a labeling that extends beyond the classical use of antipsychotics in schizophrenia and schizoaffective disorder. With some variability among the major pharmaceutical markets, it is also approved to treat manic and mixed episodes in bipolar I disorder, psychosis or inappropriate behavior in dementia, and irritability in children with autistic disorder. The additional therapeutic areas where clinical investigations of risperidone LAI have been reported include bipolar disorder and borderline personality disorder.

Borderline personality disorder is notoriously difficult to treat, and the typical deficiencies in impulse control which characterizes these patients frequently results in a low degree of compliance with medication regimes which include antipsychotics such as risperidone. In a small study (12 patients), a 6-month treatment course with risperidone LAI was associated with significant improvement on the CGI score ( $\mathrm{t}: 5.7-4.0 ; \mathrm{p}<0.01)$ and in the Global Assessment of Functioning (t: $-4.5 ; \mathrm{gl}: 10 ; \mathrm{p}<0.01)$. Clinical improvement was robust after the first month of treatment and tolerability was excellent, with treatment-related symptoms limited to mild psychomotor slowing and no emergent extrapyramidal symptoms observed (az-Marsa et al 2008).

Although acute episodes in bipolar disorder require immediate intervention, long-term maintenance therapy is of particular importance in this chronic recurrent illness. As in schizophrenia, non-adherence to pharmacotherapy (mainly the classical regimens of lithium or valproate) is widespread, and a major contributor to relapse. Studies suggest that a third of bipolar patients fail to take more than $70 \%$ of their prescribed medication (Scott and Pope 2002). As with other antipsychotics, oral risperidone (as a monotherapy or added to the basic regimen) has been shown not only to assist the 
treatment of acute manic or depressive episodes but also to provide benefit in continued pharmacotherapy; replacing or supplementing it with the long-acting intramuscular version might confer benefits similar to those seen in schizophreniform disorders.

In a Canadian 6-month prospective open-label pilot trial, in which 49 patients with bipolar disorder who were treated with a mood stabilizer and an oral second-generation antipsychotic at baseline were randomized to either continue their respective antipsychotic regimen or to be switches to risperidone LAI, the changeover to injectible risperidone did not cause significant changes in efficacy or safety parameters, indicating its therapeutic equivalence with oral antipsychotic add-on therapies (Yatham et al 2007). A Korean trial with an essentially equivalent design which enrolled only 12 patients but followed them for 12 months produced similar results (Han et al 2007). The Young Mania Rating Scale (YMRS), the CGI-S, and the ESRS had been used as outcome measures in both trials. Preliminary confirmatory information to this effect is also available for bipolar I and II patients with predominantly depressive symptoms who were treated with risperidone LAI for 2 years (Malempati et al 2008).

\section{Paliperidone - a new treatment opportunity}

An interesting potential alternative to risperidone LAI is its active metabolite, 9-hydroxy-risperidone (paliperidone), which has become available as a drug in its own right for the acute and maintenance treatment in 2007. The receptor interaction profile of paliperidone is essentially the same as for its parent drug, ie, its action is believed to be mediated mainly through antagonism at dopamine D2 receptors and serotonin 5-HT2A receptors while it has little activity at muscarinic receptors and hence, little potential for anticholinergic side effects while the preponderance for causing hyperprolactinemia can be expected to be the same (Knegtering et al 2005). The marketed form of paliperidone uses an extendedrelease once-daily oral formulation based on an inert osmotic tablet. Its clinical efficacy has been extensively reviewed (Fowler et al 2008; Nussbaum and Stroup 2008).

At therapeutic doses, most of the drug is excreted unchanged through the kidneys (Veirmeir et al 2008) and its minimal hepatic metabolism might offer a safety advantage over its parent drug in patients with liver impairment and those who use other prescription drugs which compete with risperidone for liver cytochrome 2D6 or induce or inhibit it, or those who carry CYP2D6 polymorphisms (Leon et al 2007). Also, the sustained-release formulation flattens the pharmacokinetic characteristics of paliperidone. No direct comparisons of paliperidone with oral or LAI risperidone have been published yet, but in schizophrenic patients who had been switched to paliperidone because they had remained symptomatic, paliperidone was significantly more effective than placebo (Canuso et al 2008). Most notably, a LAI formulation of paliperidone palmitate, based on nanocrystal technology, is in Phase III clinical development; if and when paliperidone LAI is broadly launched, it will be particularly rewarding to compare its safety record with that of risperidone LAI.

\section{Summary and discussion}

The new long-acting formulation of risperidone totally transforms the treatment schedule, from a tablet which the patient is asked to swallow once or twice daily to an intramuscular injection administered by a healthcare professional every 2 weeks. From the physician's perspective the immediate points to be made in favor of such an injectable formulation concern increased efficacy because plasma levels remain in the therapeutic window for weeks instead of days, and increased drug safety because the potential for overdosing (either inadvertent or deliberate, including suicide attempts) is virtually eliminated. In both cases the improvement is due to the fact that the LAI form removes responsibility for adherence to the therapeutic schedule from patients who frequently lack insight not only into the nature and severity of their condition but also into the consequences of noncompliance with their medication regimen.

With the top-level data publicly available today it is very difficult to differentiate any potential direct pharmacokinetic benefit which risperidone LAI might have over the tablet form, beyond what results from the LAI form ensuring drug levels in plasma (and by implication, also in the brain) that consistently remain in the therapeutic range. However, it is fair to assume, in keeping with the long experience with first-generation depot formulations of antipsychotic drugs, that ensured compliance is probably responsible for most of the increased therapeutic efficacy and reduced extrapyramidal symptoms of risperidone LAI relative to its oral formulations. The risk of hyperprolactinemia, which risperidone shares with older neuroleptics, and which can precipitate side effects such as sexual dysfunction, infertility, and osteoporosis, cannot be expected to be alleviated by a LAI formulation, because the active metabolite, 9-OH-risperidone, appears to be responsible rather than risperidone itself (Knegtering et al 2005).

While this might well be debated further, it can be definitely stated that therapeutic efficacy of risperidone LAI in 
schizophreniform disorders is significant even for patients previously treated with oral risperidone (see Schmauss et al 2007), and that this benefit is maintained during continued treatment for periods that may exceed 2 years. The time course of treatment-emergent events during extended studies consistently suggests that patients tend to adapt to risperidone LAI treatment early, with a level of extrapyramidal symptoms that is equivalent to, or better than, oral risperidone.

The rare but potentially life-threatening cardiac events caused by atypical antipsychotics, which are threshold-types of events triggered by excessive plasma levels of the drug, should be an even less significant risk with the injectable form than it is with risperidone tablets. Indeed, in some studies QTc interval prolongation seen with risperidone LAI was even lower than with placebo. In this context it should also be noted that in most cases the amount of risperidone introduced into the patient's body while using the LAI formulation is only about half as high as with the tablet form; typical oral doses of 4-6 mg/day are bioequivalent to $25-37.5 \mathrm{mg}$ of the LAI form every 2 weeks. Although risperidone is not known for causing pronounced gastrointestinal or hepatic side effects, reducing the burden on the intestinal drug transporters and on the liver could be beneficial in multimedicated patients, especially in the elderly.

These obvious benefits should far outweigh the few specific risks that any microparticle-based injectable drug formulation can be expected to have. Although the microparticles are designed to decompose in muscle tissue in the vicinity of the injection site, it is conceivable that some might leak into the circulation intact, either if a minor vein is damaged during injection or as a consequence of later tissue trauma near the injection site. Theoretically this could cause transient occlusion of capillary microvessels, which (probably coupled with the unintended local release of the active priciple) could be critical in some tissues, especially in capillary retinal vessels. However, no such cases have been conclusively demonstrated for risperidone LAI or an injectable form of leuprolide acetate which is based on very similar microspheres, and has been in use longer.

In summary, risperidone LAI - the first long-acting injectable formulation of a second-generation antipsychotic drug to reach the world market - exhibits an efficacy and safety profile which in the clinical practice of schizophrenia and schizoaffective disorder treatment is superior to that of the tablet formulation. As an add-on therapy in bipolar disorder, it appears to be equivalent to the oral formulation in terms of both efficacy and safety, but published data are still relatively limited in this application. As for the several other psychiatric disorders where oral risperidone has already been clinically investigated, the community can justifiably expect more clinical studies to be undertaken with risperidone LAI.

\section{Disclosures}

The author reports no conflicts of interest.

\section{References}

az-Marsa M, Galian M, Montes A, et al. 2008. Long-acting injectable risperidone in treatment resistant borderline personality disorder. A small series report. Actas Esp Psiquiatr, 36:70-4.

Bachmann S, Bottmer C, Schroder J. 2008. One-year outcome and its prediction in first-episode schizophrenia-a naturalistic study. Psychopathology, 41:115-23.

Byerly MJ, Nakonezny PA, Lescouflair E. 2007. Antipsychotic medication adherence in schizophrenia. Psychiatr Clin North Am, 30:437-52.

Canuso CM, Youssef EA, Bossie CA, et al. 2008. Paliperidone extendedrelease tablets in schizophrenia patients previously treated with risperidone. Int Clin Psychopharmacol, 23:209-15.

Cheng YH, Illum L, Davis SS. 1998. A poly(D,L-lactide-co-glycolide) microsphere depot system for delivery of haloperidol. $J$ Control Release, 55:203-12.

Curtis VA, Katsafouros K, Moller HJ, et al. 2008. Long-acting risperidone improves negative symptoms in stable psychotic patients. $J$ Psychopharmacol. In press.

Dolder CR, Lacro JP, Dunn LB, et al. 2002. Antipsychotic medication adherence: is there a difference between typical and atypical agents? Am J Psychiatry, 159:103-8.

Eerdekens M, Van Hove I, Remmerie B, et al. 2004. Pharmacokinetics and tolerability of long-acting risperidone in schizophrenia. Schizophr Res, 70:91-100.

Emsley R, Medori R, Koen L, et al. 2008. Long-acting injectable risperidone in the treatment of subjects with recent-onset psychosis: a preliminary study. J Clin Psychopharmacol, 28:210-3.

Fleischhacker WW, Eerdekens M, Karcher K et al. 2003. Treatment of schizophrenia with long-acting injectable risperidone: a 12-month open-label trial of the first long-acting second-generation antipsychotic. J Clin Psychiatry, 64:1250-7.

Fleischhacker WW, Rabinowitz J, Kemmler G, et al. 2005. Perceived functioning, well-being and psychiatric symptoms in patients with stable schizophrenia treated with long-acting risperidone for 1 year. Br J Psychiatry, 187:131-6.

Fowler JA, Bettinger TL, Argo TR. 2008. Paliperidone extended-release tablets for the acute and maintenance treatment of schizophrenia. Clin Ther, 30:231-48.

Gefvert O, Eriksson B, Persson P, et al. 2005. Pharmacokinetics and D2 receptor occupancy of long-acting injectable risperidone (Risperdal Consta) in patients with schizophrenia. Int J Neuropsychopharmacol, $8: 27-36$.

Gharabawi GM, Bossie CA, Zhu Y, et al. 2005. An assessment of emergent tardive dyskinesia and existing dyskinesia in patients receiving longacting, injectable risperidone: results from a long-term study. Schizophr Res, 77:129-39.

Gilmer TP, Dolder CR, Lacro JP, et al. 2004. Adherence to treatment with antipsychotic medication and health care costs among Medicaid beneficiaries with schizophrenia. Am J Psychiatry, 161:692-9.

Han C, Lee MS, Pae CU, et al. 2007. Usefulness of long-acting injectable risperidone during 12-month maintenance therapy of bipolar disorder. Prog Neuropsychopharmacol Biol Psychiatry, 31:1219-23.

Jann MW, Ereshefsky L, Saklad SR. 1985. Clinical pharmacokinetics of the depot antipsychotics. Clin Pharmacokinet, 10:315-33.

Kane JM, Eerdekens M, Lindenmayer JP, et al. 2003. Long-acting injectable risperidone: efficacy and safety of the first long-acting atypical antipsychotic. Am J Psychiatry, 160:1125-32. 
Kane JM. 2007. Treatment adherence and long-term outcomes. CNS Spectr, 12(Suppl 17):21-6.

Kissling W, Glue, P, Medori R, et al. 2007. Long-term safety and efficacy of long-acting risperidone in elderly psychotic patients. Hum Psychopharmacol, 22:505-13.

Knapp M, King D, Pugner K, et al. 2004. Non-adherence to antipsychotic medication regimens: associations with resource use and costs. $\mathrm{Br} \mathrm{J}$ Psychiatr, 184:509-16.

Knegtering R, Baselmans P, Castelein S, et al. 2005. Predominant role of the 9-hydroxy metabolite of risperidone in elevating blood prolactin levels. Am J Psychiatry, 162:1010-2.

Knox ED, Stimmel GL. 2004. Clinical review of a long-acting, injectable formulation of risperidone. Clin Ther, 26:1994-2002.

Lasser R, Bossie CA, Gharabawi G, et al. 2004. Efficacy and safety of long-acting risperidone in stable patients with schizoaffective disorder. $J$ Affect Disord, 83:263-75.

Lasser RA, Bossie CA, Gharabawi GM, et al. 2005. Remission in schizophrenia: Results from a 1-year study of long-acting risperidone injection. Schizophr Res, 77:215-27.

Lasser RA, Bossie CA, Zhu Y, et al. 2004. Efficacy and safety of long-acting risperidone in elderly patients with schizophrenia and schizoaffective disorder. Int J Geriatr Psychiatry, 19:898-905.

Lasser RA, Bossie CA, Zhu Y, et al. 2007. Long-acting risperidone in young adults with early schizophrenia or schizoaffective illness. Ann Clin Psychiatry, 19:65-71.

Lauriello J, McEvoy JP, Rodriguez S, et al. 2005. Long-acting risperidone vs placebo in the treatment of hospital inpatients with schizophrenia. Schizophr Res, 72:249-58.

Leal A, Rosillon D, Mehnert A, et al. 2004. Healthcare resource utilization during 1-year treatment with long-acting, injectable risperidone. Pharmacoepidemiol Drug Saf, 13:811-6.

Leon J, Susce MT, Pan RM, et al. 2007. A study of genetic (CYP2D6 and $\mathrm{ABCB} 1)$ and environmental (drug inhibitors and inducers) variables that may influence plasma risperidone levels. Pharmacopsychiatry, 40:93-102.

Lieberman JA, Stroup TS, McEvoy JP, et al. 2005. Effectiveness of antipsychotic drugs in patients with chronic schizophrenia. N Engl J Med, 353:1209-23.

Lindenmayer JP, Eerdekens E, Berry SA, et al. 2004. Safety and efficacy of long-acting risperidone in schizophrenia: a 12-week, multicenter, open-label study in stable patients switched from typical and atypical oral antipsychotics. J Clin Psychiatry, 65:1084-89.

Llorca PM, Sacchetti E, Lloyd K, et al. 2008. Long-term remission in schizophrenia and related psychoses with long-acting risperidone: results obtained in an open-label study with an observation period of 18 months. Int J Clin Pharmacol Ther, 46:14-22.

Malempati RN, Bond DJ, Yatham LN. 2008. Depot risperidone in the outpatient management of bipolar disorder: a 2-year study of 10 patients. Int Clin Psychopharmacol, 23:88-94.

Mannaert E, Vermeulen A, Remmerie B, et al. 2005. Pharmacokinetic profile of long-acting injectable risperidone at steady-state: comparison with oral administration. Encephale, 31:609-15.

Marinis TD, Saleem PT, Glue P, et al. 2007. Switching to long-acting injectable risperidone is beneficial with regard to clinical outcomes, regardless of previous conventional medication in patients with schizophrenia. Pharmacopsychiatry, 40:257-63.

McEvoy JP. 2006. Risks versus benefits of different types of long-acting injectable antipsychotics. J Clin Psychiatry, 67(Suppl 5):15-8.
Mohl A, Westlye K, Opjordsmoen S, et al. 2004. Results of direct switching to long-acting injectable risperidone in patients with schizoaffective disorder [poster]. 12th Biennial Winter Workshop on Schizophrenia, Davos, Switzerland. Poster \#347.

Moller HJ, Llorca PM, Sacchetti E, et al. 2005. Efficacy and safety of direct transition to risperidone long-acting injectable in patients treated with various antipsychotic therapies. Int Clin Psychopharmacol, 20(3):121-30.

Nesvag R, Hendset M, Refsum H, et al. 2006. Serum concentrations of risperidone and 9-OH risperidone following intramuscular injection of long-acting risperidone compared with oral risperidone medication. Acta Psychiatr Scand, 114:21-6.

Nussbaum A, Stroup TS. 2008. Paliperidone for schiphrenia. Cochrane Database Syst Rev, CD006369.

Olfson M, Mechanic D, Hansell S, et al. 2000. Predicting medication noncompliance after hospital discharge among patients with schizophrenia. Psychiatr Serv, 51:216-22.

Parellada E, Andrezina R, Milanova V, et al. 2005. Patients in the early phases of schizophrenia and schizoaffective disorders effectively treated with risperidone long-acting injectable. J Psychopharmacol, 19(Suppl 5):5-14.

Remington G, Marno D, Labelle A, et al. 2006. A PET study evaluating dopamine D2 receptor occupancy for long-acting injectable risperidone. Am J Psychiatry, 163:396-401.

Saleem P, Firmino H, Psiquiatria S, et al. 2004. Young patients (18-30 years) with schizophrenia and schizoaffective disorder: results of direct switching to long-acting injectable risperidone (StoRMi trial) [poster]. 12th Biennial Winter Workshop on Schizophrenia, Davos, Switzerland.

Schmauss M, Sacchetti E, Kahn JP, et al. 2007. Efficacy and safety of risperidone long-acting injectable in stable psychotic patients previously treated with oral risperidone. Int Clin Psychopharmacol, 22:85-92.

Schooler N, Rabinowitz J, Davidson M, et al. 2005. Risperidone and haloperidol in first-episode psychosis: a long-term randomized trial. Am J Psychiatry, 162:947-53.

Scott J, Pope M. 2002. Nonadherence with mood stabilizers: prevalence and predictors. J Clin Psychiatry, 63:384-90.

Simpson GM, Mahmoud RA, Lasser RA, et al. 2006. A 1-year doubleblind study of 2 doses of long-acting risperidone in stable patients with schizophrenia or schizoaffective disorder. J Clin Psychiatry, 67:1194-1203.

Suzuki K, Price JC. 1985. Microencapsulation and dissolution properties of a neuroleptic in a biodegradable polymer, poly(d,1-lactide). J Pharm Sci, 74:21-4.

Velligan DI, Wang M, Diamond P, et al. 2007. Relationships among subjective and objective measures of adherence to oral antipsychotic medications. Psychiatr Serv, 58:1187-92.

Veirmeir M, Naessens I, Remmerie B, et al. 2008. Absorption, metabolism and excretion of paliperidone, a new monoaminergic antagonist, in humans. Drug Metab Dispos, 36:769-79.

Weiden PJ, Buckley PF, Grody M. 2007. Understanding and treating "firstepisode" schizophrenia. Psychiatr Clin North Am, 30:481-510.

Weiden PJ. 2007. Understanding and addressing adherence issues in schizophrenia: from theory to practice. J Clin Psychiatry, 68(Suppl 14):14-9.

Yatham LN, Fallu A, Binder CE. 2007. A 6-month randomized open-label comparison of continuation of oral atypical antipsychotic therapy or switch to long acting injectable risperidone in patients with bipolar disorder. Acta Psychiatry Scand Suppl, 434:50-6. 
